\title{
Proceeding
}

Supplementary Issue: Winter Conferences of Sports Science. Costa Blanca Sports Science Events, 22-23 March 2021. Alicante, Spain.

\section{Circuit training as a method of adaptation and prevention for people with type 2 diabetes}

\author{
MARIA SALIERNO 14 , ROSARIO CERUSO ${ }^{1}$, ITALO SANNICANDRO², GAETANO ALTAVILLA ${ }^{1}$ \\ ${ }^{1}$ University of Salerno, Italy \\ 2University of Foggia, Italy
}

\begin{abstract}
The problem encountered in the diabetic population is lack of time or a prolonged exercise session. The primary purpose of this study was, therefore, to check whether a reduced training session such as 40-minute circuit training was able to optimize $\mathrm{VO}_{2}$ max levels, to identify factors that improve adherence to physical exercise. A sample of 30 subjects with an average age of 50 years (with type 2 diabetes mellitus) has been recruited in random mode. Subjects did a circuit training workout for eight weeks with a frequency of 3 weekly sessions of 40 minutes each for a total of 120 minutes per week. The 6-minute walking test was administered in and out. The T-test for dependent samples was used to detect the difference between the two groups ( $p<$ .05). The circuit training program has led to an increase in the level of cardiorespiratory form. The average $\mathrm{VO}_{2}$ max increased significantly $(p<.05)$ compared to the basic values, with an increase of $+6.08 \%$. The circuit training carried out for 8 weeks, lasting 40 minutes with intensity between 50 and $75 \%$ of the $\mathrm{VO}_{2} \max$, is able to achieve appreciable improvements on cardiorespiratory fitness.

Keywords: Endurance training; Aerobic training; Type 2 diabetes; Circuit training, $\mathrm{VO}_{2}$ max.
\end{abstract}

\section{Cite this article as:}

Salierno, M., Ceruso, R., Sannicandro, I., \& Altavilla, G. (2021). Circuit training as a method of adaptation and prevention for people with type 2 diabetes. Journal of Human Sport and Exercise, 16(3proc), S1045-S1054. https://doi.org/10.14198/jhse.2021.16.Proc3.22

Corresponding author. University of Salerno, Italy.

E-mail: m.salierno3@studenti.unisa.it

Abstract submitted to: Winter Conferences of Sports Science. Costa Blanca Sports Science Events, 22-23 March 2021. Alicante, Spain.

JOURNAL OF HUMAN SPORT \& EXERCISE ISSN 1988-5202.

(c) Faculty of Education. University of Alicante.

doi:10.14198/jhse.2021.16.Proc3.22 


\section{INTRODUCTION}

Diabetes mellitus is a social disease that affects about $4.5 \%$ of the population in Italy, or about 3 million Italians with different severity from subject to subject. In the United States alone, it affects about $9.3 \%$ of the population, or 29.1 million people, of whom 21 million are diagnosed and 8.1 million are still considered undiagnosed (Fatone et al., 2010). Physical activity is today considered very useful for general preventive action to specific diseases (Fischetti et al., 2017) and for health purposes (Gaetano, 2017, Tiziana et al., 2017), as it is able to limit the onset and progression of the disease and favour a better control of the metabolic state, so the physical training in pandemic state has to compensate in alternative mode (Raiola, Di Domenico, 2012, Raiola, Aliberti, 2021, Raiola et al., 2021) . The A.N.I.A.D (Italian National Association of Diabetic Athletes), guarantees a fundamental contribution to the promotion of sport with the important objective of spreading a healthy culture of physical activity and sport among type 1 and type 2 diabetic subjects, in order to improve the level of awareness and therapeutic education. Physical training to enlarge activities level, according to scientific principles (Altavilla et al., 2018ab), is able, in fact, to increase insulin sensitivity and reduce its plasma levels in patients with hyperinsulinemia. In addition, it helps maintain the right body weight, improve dyslipidemia, and lower blood pressure, leads to an increase in metabolically active muscle tissue and improves cardiovascular health (Cauza et al., 2005). Both aerobic and endurance exercise are associated with a decreased risk of type II diabetes (Hansen et al., 2009). A large prospective study has shown that an expenditure of $500 \mathrm{kcal}(2100 \mathrm{~kJ})$ per week leads to a reduction in the incidence of the disease of $6 \%$ (RR 0.94, Cl 95\% -0.90-0.98), with particularly obvious benefits among high-risk individuals (e.g., individuals with high BMI). Moderate physical activity $(\geq 5.5 \mathrm{MET})$ for at least 40 minutes per week and cardiovascular fitness (>31 $\mathrm{ml} \mathrm{O}_{2}$ per $\mathrm{kg}$ per min.) is protective against type II diabetes (Paoli et al., 2013). Exercise is also effective in managing the disease. Several clinical studies and metanalysis in this regard, have in fact shown how aerobic training and in particular resistance training are useful for the control of glycemic homeostasis and lead to a decrease in mortality from cardiovascular diseases and other causes in diabetics and in subjects with metabolic syndrome (Hawkins et al., 2007). In addition, motor activity can also be useful for glycemic control in subjects with this pathology, with an effectiveness that increases as the intensity of exercise increases (Heesch et al., 2004). The systematic involvement of diabetic subjects in exercise programs could become a powerful means of improving the quality of life of subjects and saving much of the public money that is generally spent on the treatment of diabetic pathology and the complications that derive from it (Jenkins et al., 2009). One of the biggest obstacles to the lasting involvement of this population of subjects in exercise programmers is the often-stated lack of time, or the too long duration of the dedicated sessions (Prior et al., 2014). Therefore, it is reasonable to assume that a shorter exercise session may be an appropriate proposal, to motivate diabetic subjects to practice physical activity in a specific vision of physical training (Raiola, 2020ab) and not in order medical activity. Thus, physical training has to apply at motor learning and biomechanics to optimize the health status (D'Elia et al., 2020, , Raiola et al., 2020) and it assess such as sport performance (D'Isanto et al., 2019).

This study aimed to verify whether a 40-minute circuit training program was able to optimize the levels of maximum oxygen consumption $\left(\mathrm{VO}_{2} \mathrm{max}\right)$, as well as other protocols, but with significantly shorter times.

\section{MATERIAL AND METHODS}

\section{Study participants}

In this study a sample of 30 subjects with an average age of 50 years (with type 2 diabetes mellitus) has been recruited in random mode. Subjects did a circuit training workout for eight weeks with a frequency of 3 weekly sessions of 40 minutes each for a total of 120 minutes per week. 
The inclusion criteria included diagnosed diabetes meeting World Health Organization (WHO) criteria, ability to walk for at least 15 minutes without care, stable clinical conditions, and underwriting informed consent. The study was carried out through the establishment of a team of scholars formed by a sports kinesiologist expert of the movement, a nutritionist biologist and a diabetologist. The nutritionist biologist first carried out an anthropometric evaluation to define effective and safe workloads in the next phase of administration of personalized physical exercise (aerobic, against resistance, balance, and flexibility).

\section{Anthropometric and body composition assessments}

Measurement of weight, height, implemented by means of a scale weighs seca professional column people, with clock scale and telescopic altimeter for medical use.

Table 1. Summary of baseline values.

Features Sample

\begin{tabular}{lcc} 
Anthropometric parameters & & \\
Weight & $95.62(18.13)$ & $/$ \\
W/H ratio & $1.0(0.11)$ & $/$ \\
BMl (kg/m²) & $34.11(6.93)$ & $/$ \\
Blood parameters & $61.23(15.66)$ & $/$ \\
HbA1c & & \\
Blood pressure & $123.85(10.53)$ & $/$ \\
Systolic (mmHg) & $75.38(5.81)$ & $/$ \\
Diastolic (mmHg)) & 21.9 & $/$ \\
Cardiovascular efficiency and recovery & $7.03 \quad(3.28)$ & $/$ \\
VO2max (ml/min/ $\left./ \mathrm{kg}^{1}\right)$ & \multicolumn{2}{c}{} \\
Ruffier Dickson &
\end{tabular}

Measurement of arm circumferences (contracted and relaxed biceps), forearm, wrist, abdomen, hips, thigh (root and medium) knee, calf and ankle through Wilmore and Behnke formula (Behnke, Wilmore,).

\begin{tabular}{|l|}
\hline Formula di Wilmore e Behnke, 1972 \\
\hline Men \\
\hline FM (\%): $495 /\{1.0324-0.19077[\log$ (waist-neck)] + 0.15456 [log (Stature)]-450 \\
\hline Gives \\
\hline FM (\%): $495 /\{1.29579-0.35004[\log$ (waist +hips-neck)] $0.22100[\log$ (Stature)]\} - 450 \\
\hline
\end{tabular}

Figure 1. Wilmore and Behnke formula for calculating $\%$ fat mass from circumferences.

\section{Analysis of the picometre}

Taking an envelope between the thumb and index finger and measuring it with a professional picometer equipped with a clock face graduated in millimetres and twentieths of a millimetre, with a measuring range of up to $80 \mathrm{~mm}$ and a constant pressure of $10 \mathrm{~g} / \mathrm{mm} 2$. The use of this tool has been validated by several scientific documentations published over the past 40 years, referring to practical applications for diagnosis in the nutritional, obesity and eating disorders sectors.

The detection points considered were those indicated by the 3 Point Skin Fold Bodyfat (Jackson et al., 1978) and the procedure indicated by Durmin and Womersley (Durnin et al., 1967). The latter, in addition to the 
methodology of calculation with the appropriate formula, can be implemented by means of the appropriate reference tables, which consider the sum of the envelopes referring to sex and age. The measures related to plicometry were detected by 4 different clinical physiologists of physical exercise, for this reason, the operator in charge of each tested subject (as well as the initial detection conditions) was taken note, in order to have the evaluation replicated only to the technician who had first performed the acquisition of the plicometry, in order to neutralize the inter-operator error.

\section{Walking test for 6 minutes (6 MWT)}

The 6-minute walking test was administered in and out. Sub-maximum test for aerobic capacity assessment in subjects with moderately impaired functional capacity (Carter et al., 2003). During the journey, the use of an oxygen concentrator or the use of a chair to rest is allowed. It is a test that takes place on a linear path of 30 meters (for example a corridor) along which the patient must walk, back and forth, for 6 minutes, at the maximum speed allowed to him (Dourado, 2011). The stopwatch starts when the subject moves the first foot forward (Church et al., 2010). The evaluator walks behind the subject to avoid the stimulation effect and records each lap with a tachometer. During the walk he shows the subject to the Borg fatigue perception scale, to understand the state of fatigue. Depending on the observation of the subject and the perception reported, it is invited to slow down, hold, or increase the walking rhythm (Hill et al., 2011). At the end of the 6 minutes, heart rate, blood pressure, oxygen saturation and distance travelled are detected. The following list reproduces the main symptoms that lead to the interruption of the test: sudden chest pain, lower limb cramps, lack of sudden strength, staggering, dizziness, paroxysmal dyspnea, pallor, abnormal sweating. To have an accurate estimate of the meters that a subject must be considered the Gibbons formula. From that formula, it's then possible to obtain, by means of a formula of conversion of the meters travelled $(0.03 \times \mathrm{m}$ travelled +3.98 ) an estimate of the $\mathrm{VO}_{2}$ max of the subject (Adeniyi, et al., 2010). Values considered normal are widely variable based on factors such as gender, age, height, weight, and overall health status. In a healthy subject the covered distance is usually between 400 and $700 \mathrm{~m}$ and oxygen saturation at the end of the test should not be lower than $93 \%$.

\begin{tabular}{|l|}
\hline Gibbons' formula \\
\hline Prediction of distance travelled \\
\hline 868.8-(2.99x age)-74,7 x Sex Coefficient \\
\hline Sex coefficient: $\mathrm{M}=0 / \mathrm{F}=1$ \\
\hline
\end{tabular}

Figure 2. Formula for predicting the distance travelled.

\begin{tabular}{|l|}
\hline 1996 - Cahalin's formula \\
\hline $\mathrm{VO}_{2}$ max prediction \\
\hline $0.03 \times$ meters travelled +3.98 \\
\hline
\end{tabular}

Figure 3. Formula for predicting $\mathrm{VO}_{2 \max }$ based on the meters covered in the 6MWT.

\section{Ruffier-Dickson recovery test, for cardiovascular efficiency}

Evaluation of heart rate recovery after physical activity. It involves a queuing movement to be performed 30 times in up to 45 seconds. Heart rate is detected before exercise (A), immediately at the end of exercise (B) and one minute after the end of the exercise $(C)$. The values of the different frequencies will be transcribed and calculated according to the formula: $A+B+C / 100$. The result obtained is compared with a special reference table. 


\section{Circuit implementing protocol}

Aerobic exercise and endurance training are the two main strategies proposals to improve the fitness and health status of healthy and diabetes subject (Jacobs et l., 2001). The American College of Sports Medicine (ACSM) recommends performing 8 to 12 repetitions per exercise for each main muscle group at an intensity that can be as high as $40 \%$ to $80 \%$ of a maximum repeat (MRI) while maintaining a level of training appropriate to the participant's level of training (D'Elia et al., 2019). It is recommended from 2 to 4 sets (series) for each muscle group, with a recovery (rest) of about 2-3 minutes at the end of each series (Garber et al., 2011). Similarly, aerobic training guidelines recommend 150 minutes per week of moderate intensity exercise ( $46 \%$ to $63 \%$ of maximum oxygen consumption, $\mathrm{VO}_{2 \max }$ ) for 30-60 minutes per session and/or 75 minutes per week of intense physical activity ( $64 \%$ to $90 \%$ of $\mathrm{VO}_{2 \max }$ ) for $20-60$ minutes per session.

In order to prevent the possible early abandonment of an exercise plan that was too long, it was thought to use a circuit training strategy that included counter-resistance training, flexibility and balance exercises, conducted with a sustained heart rate, so that you can adequately stimulate the respiratory and cardiocirculatory system, in a reasonably shorter time frame (40 minutes total training, that is, about $30-35 \%$ less time) than a classic aerobic or training session with overloads (Altavilla et al., 2018). The exercises of a circus have been prepared in an order of succession of three muscular groups different between training and active recovery (Jacobson et al., 1994). The stations planned within the circuit were equal to 8 , one for each exercise. A start was chosen for the next type of circuit in which the 30 people were divided into 5 groups of 6 people who were arranged near the first station in such a way as to start the circuit one at a time. This mode of rotation has made it possible to modulate the load and the sequence of the exercises in a very precise way. In addition, the wait at the beginning of the circuit, was transformed into the necessary recovery time at the end of the route.

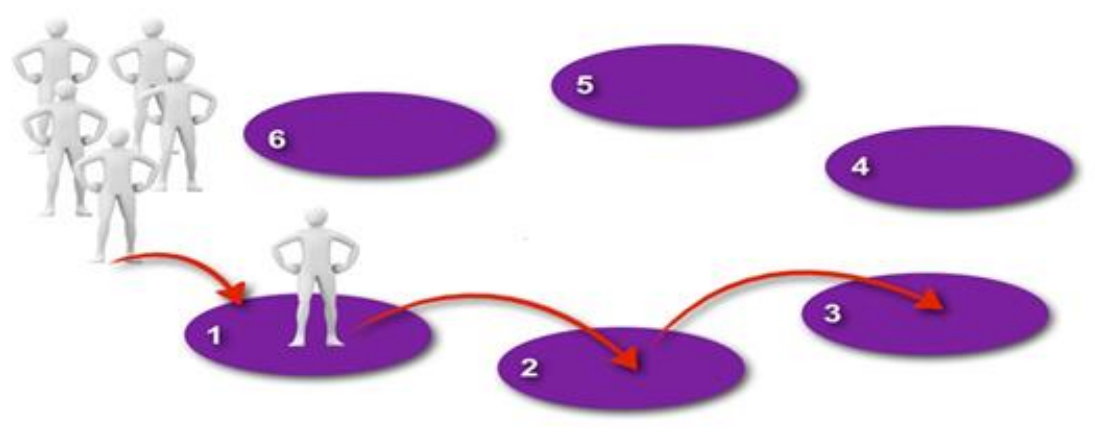

Figure 4. Graphical exemplification of a circuit with a later start; protocol used for this work.

Each training session lasted 40 minutes broken down as follows:

- Initial general warm-up phase lasting 5 minutes.

- 30-minute training.

- Cool down phase lasting 5 minutes.

The workloads were defined in percentage terms on the basis of the measurements obtained from the ergometric test for aerobic exercise. For resistance exercises, the expected loads started from a minimum initial of $50 \%$ of $1 \mathrm{MRI}$ and then continued up to $65 \%$ of $1 \mathrm{RM}$. 
The exercises chosen and that were part of the circuit in a stable way were:

- Leg bends with overload (squat).

- Forearm push-ups on the arm with dumbbell curl.

- Arms thrusts up with handlebars (military press).

- Chest thrusts at TRX (TRX Push-Up).

- Folding of the arms on the ground of the breasts with flexed legs (modified Push-Up).

- Alternating balance on one leg standing.

- Maintain the squat position at the Easy Tone step.

- Arm circumference.

- Supine bust push-ups on swiss ball (swiss ball abdominal crunch).

- Seated stretching for hamstrings and lumbar area (Sit \& Reach).

- Stretching for standing quadriceps with passive grip of the flexed leg.

- Stretching for anterior and posterior deltoid.

In the first period, the emphasis was on joint mobility and balance, reducing strength exercises. Gradually, the strength exercises have been increased, but without eliminating the training of the other qualities altogether.

\section{RESULTS}

The results detected by the T-test show that in relation to $29 \mathrm{df}$ and placing as a level of significance $a=.05$, one has that acceptance region $-1.69 \leq x \leq 1.69$. So, since the value of the stat $t=-444.15$ does not fall within the range and belongs to the reject region, we can reject the hypothesis $(\mathrm{H} 0)$ that assumed an equal value of the two averages and we can accept the alternative hypothesis that assumed, instead, a variation of the two averages.

Table 2. Recruitment of 6 minutes walking test inbound and outbound values.

\begin{tabular}{lcc}
\hline Subjects & VO $_{\text {2max }}$ before training & VO $_{\text {2max }}$ after training \\
\hline Subject 1 & 601 & 800 \\
Subject 2 & 602 & 801 \\
Subject 3 & 604 & 800 \\
Subject 4 & 606 & 802 \\
Subject 5 & 601 & 805 \\
Subject 6 & 603 & 804 \\
Subject 7 & 604 & 805 \\
Subject 8 & 602 & 803 \\
Subject 9 & 600 & 802 \\
Subject 10 & 602 & 800 \\
Subject 11 & 602 & 804 \\
Subject 12 & 600 & 803 \\
Subject 13 & 601 & 805 \\
Subject 14 & 603 & 806 \\
Subject 15 & 600 & 800 \\
Subject 16 & 604 & 799 \\
Subject 17 & 605 & 802 \\
Subject 18 & 600 & 798 \\
Subject 19 & 605 & 802 \\
\hline
\end{tabular}




\begin{tabular}{lll}
\hline Subject 20 & 605 & 804 \\
Subject 21 & 603 & 801 \\
Subject 22 & 602 & 798 \\
Subject 23 & 605 & 805 \\
Subject 24 & 603 & 802 \\
Subject 25 & 603 & 800 \\
Subject 26 & 604 & 803 \\
Subject 27 & 603 & 804 \\
Subject 28 & 602 & 800 \\
Subject 29 & 602 & 802 \\
Subject 30 & 600 & 801 \\
\hline
\end{tabular}

Table 3. t-test for dependent samples.

\begin{tabular}{|c|c|c|c|c|c|c|c|c|}
\hline \multicolumn{9}{|l|}{\begin{tabular}{|l|} 
Paired Samples Test \\
\end{tabular}} \\
\hline & \multicolumn{5}{|c|}{ Paired Differences } & \multirow{3}{*}{$\mathrm{t}$} & \multirow{3}{*}{ df } & \multirow{3}{*}{ Sig. (2-tailed) } \\
\hline & \multirow{2}{*}{ Mean } & \multirow{2}{*}{$\begin{array}{l}\text { Std. } \\
\text { Deviation }\end{array}$} & \multirow{2}{*}{$\begin{array}{l}\text { Std. Error } \\
\text { Mean }\end{array}$} & \multicolumn{2}{|c|}{$\begin{array}{l}95 \% \text { Confidence Interval } \\
\text { of the Difference }\end{array}$} & & & \\
\hline & & & & Lower & Upper & & & \\
\hline \begin{tabular}{|l|l|} 
Pair 1 & before - after \\
\end{tabular} & -199.46667 & 2.45979 & .44909 & -200.38517 & -198.54817 & -444.153 & 29 & .000 \\
\hline
\end{tabular}

Table 4. Summary of the results related to the improvement of aerobic capacity.

\begin{tabular}{lc}
\hline & $\mathrm{VO}_{2 \max }(\mathrm{ml} / \mathbf{k g} / \mathrm{min})$ \\
\hline Pre-workout & 21.9 \\
SD & 0.70 \\
Post-workout & 27.98 \\
SD & 0.70 \\
$\Delta \%$ & $6.08 \%$ \\
\hline
\end{tabular}

Table 5. Summary of the results related to the recovery index.

\begin{tabular}{lc}
\hline & Recovery Index \\
\hline Pre-workout & 7.03 \\
SD & 3.28 \\
Post-workout & 6.67 \\
SD & 2.82 \\
$\Delta$ & -.36 \\
$\Delta \%$ & $-5.12 \%$ \\
$P$ & .46 \\
\hline
\end{tabular}

Table 6. Summary of the results related to anthropometric parameters and body composition.

\begin{tabular}{lccccc}
\hline & Waist Circumference $\mathbf{( c m )}$ & W/HR & $\boldsymbol{\Sigma}$ Circumference $(\mathbf{c m})$ & $\boldsymbol{\Sigma}$ Skin Fold $(\mathbf{c m})$ & $\begin{array}{c}\text { BMI } \\
\left(\mathbf{k h} / \mathbf{m}^{2}\right)\end{array}$ \\
\hline Pre-workout & 112.6 & 1 & 567.01 & 181.77 & 34.11 \\
SD & 15.49 & 0.09 & 49.24 & 53.59 & 6.93 \\
Post-workout & 111.39 & 1 & 563.49 & 166.13 & 33.85 \\
SD & 11.29 & 0.11 & 51.08 & 47.47 & 6.97 \\
$\Delta$ & -1.2 & 0 & -3.51 & -15.64 & -.25 \\
$\Delta \%$ & $-1.07 \%$ & $0.00 \%$ & $-0.62 \%$ & $-8.60 \%$ & $-.76 \%$ \\
P & .504 & .969 & .074 & .019 & .142 \\
\hline \hline
\end{tabular}




\section{DISCUSSION}

The circuit training program has led to an increase in the level of cardiorespiratory form. The average $\mathrm{VO}_{2 m a x}$ increased significantly $(p<.05)$ compared to the base values, with an increase of $+6.08 \%$. The percentage difference was derived from the pre-workout $\mathrm{VO}_{2 \max }$ value of $21.9 \mathrm{ml} / \mathrm{kg} / \mathrm{min}$ and the post-workout value of $27.98 \mathrm{ml} / \mathrm{kg} / \mathrm{min}$ showing an increase in aerobic capacity. No subjects reported musculoskeletal injuries and only two subjects reported mild and bearable muscle aches. None of the participants reported experiences of post-exercise hypoglycemia. The importance of this parameter $\left(\mathrm{VO}_{2 \max }\right)$ is closely related to the fact that low cardiorespiratory capacity is correlated as a powerful predictive, independent and mortality factor in people with diabetes. A 2003 meta-analysis (Boulé, et al., 2003) with 7 studies analysed, reported that aerobic exercises of 49 minutes per session, with intensity between $50 \%$ and $75 \% \mathrm{VO}_{2 \max }$ for 20 weeks, are able to achieve an increase of $11.8 \%$ in the subjects of the various jobs considered. Our protocol, while reporting increases below Boulè's meta-analysis, returned a significant improvement of $6.08 \%$, also confirmed by the return to normal values of resting heart rate, a sign of an improvement in cardiorespiratory efficiency. We can therefore say that the initial goal of verifying whether a reduced training session of 40 minutes in circuit form, raised the values of maximum oxygen consumption, was achieved, since with the Ttest there was a noticeable variation between the two averages of the maximum oxygen consumption in and out.

\section{CONCLUSION}

The circuit training carried out for 8 weeks, lasting 40 minutes with intensity between 50 and $75 \%$ of the $\mathrm{VO}_{2 \max }$, is able to obtain appreciable improvements on cardiorespiratory form, muscle level and also on glided hemoglobin $(\mathrm{HbA1C})$. However, further research would be needed to understand how to improve the adhesion mechanisms of diabetics and to clarify the physiological mechanisms involved in the results observed so far.

\section{REFERENCES}

Adeniyi, A. F., Uloko, A. E., \& Sani-Suleiman, I. (2010). Relationship Between the 6-minute Walk Test and Correlates of Type 2 Diabetes: Indication for caution in exercise prescription. African Journal of Physiotherapy and Rehabilitation Sciences, 2(1), 21-24. https://doi.org/10.4314/ajprs.v2i1.62602

Altavilla, G., D'Isanto, T., Di Tore, A.P., Raiola, G. (2018a). Free throw and outcomes: Pilot study on intensive training versus extensive one. Journal of Human Sport and Exercise, 13 (3), pp. 494-503. https://doi.org/10.14198//hse.2018.133.02

Altavilla, G., D'Elia, F., Raiola, G. (2018b) A brief review of the effects of physical activity in subjects with cardiovascular disease: An interpretative key. Sport Mont, 16 (3), pp. 103-106. https://doi.org/10.26773/smi.181018

Boulé, N. G., Kenny, G. P., Haddad, E., Wells, G. A., \& Sigal, R. J. (2003). Meta-analysis of the effect of structured exercise training on cardiorespiratory fitness in Type 2 diabetes mellitus. Diabetologia, 46(8), 1071-1081. https://doi.org/10.1007/s00125-003-1160-2

Carter, R., Holiday, D. B., Nwasuruba, C., Stocks, J., Grothues, C., \& Tiep, B. (2003). 6-minute walk work for assessment of functional capacity in patients with COPD. Chest, 123(5), 1408-1415. https://doi.org/10.1378/chest.123.5.1408

Cataldi, S., Francavilla, V.C., Bonavolontà, V., De Florio, O., Carvutto, R., De Candia, M., Latino, F., Fischetti, F. (2021). Proposal for a fitness program in the school setting during the covid 19 pandemic: Effects of an 8-week crossfit program on psychophysical well-being in healthy adolescents. 
International Journal of Environmental Research and Public Health, 18 (6), art. no. 3141, pp. 1-12. https://doi.org/10.3390/ijerph18063141

Cauza, E., Hanusch-Enserer, U., Strasser, B., Ludvik, B., Metz-Schimmerl, S., Pacini, G., ... \& Haber, P. (2005). The relative benefits of endurance and strength training on the metabolic factors and muscle function of people with type 2 diabetes mellitus. Archives of physical medicine and rehabilitation, 86(8), 1527-1533. https://doi.org/10.1016/j.apmr.2005.01.007

Church, T. S., Blair, S. N., Cocreham, S., Johannsen, N., Johnson, W., Kramer, K., ... \& Earnest, C. P. (2010). Effects of aerobic and resistance training on hemoglobin A1c levels in patients with type 2 diabetes: a randomized controlled trial. Jama, 304(20), 2253-2262. https://doi.org/10.1001/jama.2010.1710

D'Elia, F., D'Isanto, T., Altavilla, G. (2019). Training and performance in the transition period. Journal of $\begin{array}{lllll}\text { Human Sport and Exercise, } 14 \text { (Proc2), pp. S258-S262. } & \end{array}$ https://doi.org/10.14198/ihse.2019.14.Proc2.15

D'Elia, D., Domenico, F.D., Isanto, T.D., Altavilla, G., Raiola, G. (2020) From biomechanics to motor learning, Acta Medica Mediterranea, 36 (5), pp. 3073-3078.

D'Isanto, T., D'Elia, F., Raiola, G., Altavilla, G. (2019) Assessment of sport performance: Theoretical aspects and practical indications, Sport Mont, 17 (1), pp. 79-82. https://doi.org/10.26773/smj.190214

Dourado, V.Z. (2011). Reference equations for the 6-minute walk test in healthy individuals. Arquivos brasileiros de cardiologia, 96(6), e128-e138. https://doi.org/10.1590/S0066-782X2011005000024

Durnin, J. V. G. A., \& Rahaman, M. M. (1967). The assessment of the amount of fat in the human body from measurements of skinfold thickness. British journal of Nutrition, 21(3), 681-689. https://doi.org/10.1079/BJN19670070

Fatone, C., Guescini, M., Balducci, S., Battistoni, S., Settequattrini, A., Pippi, R., ... \& De Feo, P. (2010). Two weekly sessions of combined aerobic and resistance exercise are sufficient to provide beneficial effects in subjects with Type 2 diabetes mellitus and metabolic syndrome. Journal of endocrinological investigation, 33(7), 489-495. https://doi.org/10.1007/BF03346630

Fischetti, F., Greco, G., Cataldi, S., Minoia, C., Loseto, G., Guarini, A. (2019) Effects of physical exercise intervention on psychological and physical fitness in lymphoma patients Medicina (Lithuania), 55 (7), art. no. 379Gaetano, A. (2016)Relationship between physical inactivity and effects on individual health status, Journal of Physical Education and Sport, 16, pp. 1069-1074. https://doi.org/10.3390/medicina55070379

Garber, C. E., Blissmer, B., Deschenes, M. R., Franklin, B. A., Lamonte, M. J., Lee, I. M., ... \& Swain, D. P. (2011). American College of Sports Medicine position stand. Quantity and quality of exercise for developing and maintaining cardiorespiratory, musculoskeletal, and neuromotor fitness in apparently healthy adults: guidance for prescribing exercise. Medicine and science in sports and exercise, 43(7), 1334-1359. https://doi.org/10.1249/MSS.0b013e318213fefb

Hansen, D., Dendale, P., Jonkers, R. A. M., Beelen, M., Manders, R. J. F., Corluy, L., ... \& Van Loon, L. J. C. (2009). Continuous low-to moderate-intensity exercise training is as effective as moderate-to high-intensity exercise training at lowering blood $\mathrm{HbA} 1 \mathrm{c}$ in obese type 2 diabetes patients. Diabetologia, 52(9), 1789-1797. https://doi.org/10.1007/s00125-009-1354-3

Hawkins, M. N., Raven, P. B., Snell, P. G., Stray-Gundersen, J., \& Levine, B. D. (2007). Maximal oxygen uptake as a parametric measure of cardiorespiratory capacity. Med Sci Sports Exerc, 39(1), 103107.

Heesch, K. C., \& Mâsse, L. C. (2004). Lack of time for physical activity: perception or reality for African American and Hispanic women?. Women \& health, 39(3), 45-62. https://doi.org/10.1300/J013v39n03_04 
Hill, K., Wickerson, L. M., Woon, L. J., Abady, A. H., Overend, T. J., Goldstein, R. S., \& Brooks, D. (2011). The 6-min walk test: responses in healthy Canadians aged 45 to 85 years. Applied physiology, nutrition, and metabolism, 36(5), 643-649. https://doi.org/10.1139/h11-075

Jacobs, P. L., Nash, M. S., \& Rusinowsky, J. W. (2001). Circuit training provides cardiorespiratory and strength benefits in persons with paraplegia. Medicine \& Science in Sports \& Exercise, 33(5), 711717. https://doi.org/10.1097/00005768-200105000-00005

Jacobson, A. M., De Groot, M., \& Samson, J. A. (1994). The evaluation of two measures of quality of life in patients with type I and type II diabetes. Diabetes care, 17(4), 267-274. https://doi.org/10.2337/diacare.17.4.267

Jackson, A. S., Pollock, M. L., \& Gettman, L. R. (1978). Intertester reliability of selected skinfold and circumference measurements and percent fat estimates. Research Quarterly. American Alliance for Health, Physical Education and Recreation, 49(4), 546-551. https://doi.org/10.1080/10671315.1978.10615569

Jenkins, S., Cecins, N., Camarri, B., Williams, C., Thompson, P., \& Eastwood, P. (2009). Regression equations to predict 6 -minute walk distance in middle-aged and elderly adults. Physiotherapy theory and practice, 25(7), 516-522. https://doi.org/10.3109/09593980802664711

Paoli, A., Pacelli, Q. F., Moro, T., Marcolin, G., Neri, M., Battaglia, G., ... \& Bianco, A. (2013). Effects of high-intensity circuit training, low-intensity circuit training and endurance training on blood pressure and lipoproteins in middle-aged overweight men. Lipids in health and disease, 12(1), 1-8. https://doi.org/10.1186/1476-511X-12-131

Prior, S. J., Blumenthal, J. B., Katzel, L. I., Goldberg, A. P., \& Ryan, A. S. (2014). Increased skeletal muscle capillarization after aerobic exercise training and weight loss improves insulin sensitivity in adults with IGT. Diabetes Care, 37(5), 1469-1475. https://doi.org/10.2337/dc13-2358

Raiola, G. (2019) Comparison of exercise and sport sciences epistemology between european research council structure panel and Italian academic system, Sport Science, 12, pp. 112-120.

Raiola, G. (2020a). Proposal of rearrangement of physical training and sport sciences methodology academic disciplines in Italian university body. Sport Science, 14 (1), pp. $43-47$.

Raiola, G. (2020b). The Movement and Sport Science in Italy towards the European Research Council. Physical Culture and Sport, Studies and Research, 86 (1):37-48. https://doi.org/10.2478/pcssr-20200011

Raiola, G., Domenico, F.D., Isanto, T.D., Altavilla, G., Elia, F.D. (2020) Biomechanics core, Acta Medica Mediterranea, 36 (5), pp. 3079-3083.

Raiola, G., Di Domenico, F. (2021) Physical and sports activity during the COVID-19 pandemic, Journal of Physical Education and Sport, 21, art. no. 49, pp. 477-482.

Raiola, G., Aliberti, S. (2021) Outdoor sports and physical activity during social distancing by sports sciences and exercise course students at the university of Salerno, Journal of Physical Education and Sport, 21, art. no. 71, pp. 612-617.

Raiola, G., Aliberti, S., Esposito, G., Altavilla, G., D'Isanto, T., D'Elia, F. (2020) How has the practice of physical activity changed during the covid-19 quarantine? a preliminary survey, Teoria ta Metodika Fizicnogo Vihovanna, 20 (4), pp. 242-247. https://doi.org/10.17309/tmfv.2020.4.07

Tiziana, D., Antonetta, M., Gaetano, A. (2017) Health and physical activity [Zdravlje i tjelesna aktivnost] Sport Science, 10 (1), pp. 100-105.

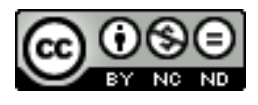

This work is licensed under a Attribution-NonCommercial-NoDerivatives 4.0 International (CC BY-NC-ND 4.0). 